\title{
Characteristics of Fruit Quality of Peach Cultivars and Hybrids in the Steppe Crimea
}

\author{
Tatyana Latsko \\ The Steppe Horticulture Laboratory, Department of Fruit Crops, Nikitsky Botanical Garden, Yalta 298648, Russian Federation
}

\begin{abstract}
The study of peach fruit quality and biochemical composition of cultivars and hybrids were conducted in terms of the steppe zone of Crimea. A total of 40 cultivars and hybrids from five periods of ripening were analyzed for content of basic biochemical components: solids, sugars, acids, polyphenolic compounds and vitamin C. The main fruit quality parameters: the size, the attractive appearance, the consistency flesh, the stone adherence to flesh, taste and others have been evaluated. As a result of studies peach cultivars with a high content of sugar in the fruit under the steppe Crimea have highlighted: Kremlyovskiy (13.6), Regina (13.2), Velvet (12.9), hybrids C7/38 (13.1) and C4/57 (12.9). Cultivars and hybrids of peach 10607, C1/227 C7/38, C7/6, C8/162, C4/147, C16/87, C4/64, Early Red Haven, Miorita, 7/221, Kremlyovskiy, 10848 are characterized by the best biochemical and morphological indices of fruits. They are recommended for State cultivar testing or use in breeding work to improve the quality of peach fruits.
\end{abstract}

Key words: Peach, hybrids, fruit quality, biochemical components, sugars, anthocyans, leucoanthocyans, catechins.

\section{Introduction}

Peach is a kind of stone fruit tree. In Crimea the share of peach in the total market is 50\%-60\% and $20 \%-30 \%$ of a total stone fruit and fruit tree production respectively. Opinions of scientists, economists and businessmen, with respect to the proportion of peach in the fruit production in the Crimean region diverge. Some believe that the peach is the main fruit crop in the Crimea, while others believe that dominant crop should be an apple tree. These differing views are due to variety of natural and climatic conditions in Crimea [1]. The flatland areas and foothills are extremely favorable for fruit crop production especially for growing peaches. In general, the environmental conditions of greater part of the Crimean peninsula meet the biological needs of the species Prunus persica L. In the winter, during deep dormancy, it is cold enough for the further development of generative buds. The temperature regime of summer months is favorable for successful

Corresponding author: Tatyana Latsko, Ph.D., research fields: breeding and seed production of fruit crops. fruit development, ripening and the accumulation a sufficient amount of sugars in them [2]. There are some problems that prevent the spread of this fruit tree in the colder area. Extreme winter cold and spring recurrent frosts are risk factors for the cultivation of peaches in the region. Recurrent spring frosts occur in the steppe and foothill areas of the Crimea in March, April, and are sometimes-in May. The second problem is a deficiency of suitable water, especially during the vegetation period, so the peach culture needs irrigation. In some years in September it is lacking heat for the ripening fruits of late and very late cultivars of a peach and nectarine. Despite these challenges peach has won special popularity among residents and guests of the peninsula and became a visiting card. Peach fruits valued primarily for an excellent balanced flavor, soft melting juicy flesh. These are rich in sugars, organic acids, macro elements, especially potassium and microelements (Fe, $\mathrm{F}, \mathrm{Mg}, \mathrm{Mn}, \mathrm{Cu}, \mathrm{Se}, \mathrm{P}, \mathrm{Zn}$ and others). Peach fruits are sources carotene, a lot of vitamins: C, group of B, PP, $\mathrm{K}_{1}$ etc. Peaches are used for dietary nutrition due their content of vitamins and biologically active substances, 
organic acids. It is very important for the resort Crimea. Local population consumes peach fruits both fresh and processed in the form of juices, purees, and fruit compotes and frozen. The quality and taste of fruits are important economic and biological characteristics, determining the commercial value of the peach cultivars. Main parameters of the fruit quality are the size (mass), the attractiveness of appearance (shape, the basic color of the fruit, the cover color), the color, texture and other characteristics of the flesh, the biochemical composition, flavor and aroma. Improving of peach fruit quality is one of the directions of breeding in the Nikitsky Botanical Garden (NBG). The fruit must be large (120-250 g), right round, flattened or oval, with a bright covering color, which occupies most of the fruit surface. There is some demand for the fruit without the coating color, pure yellow or creamy white. Recently, the demand for flat fruits increased [3, 4]. The fruit skin has a mild gentle pubescence, suede or velvet. Fruits with yellow flesh (from of a light yellow to orange hue) are most popular. A certain amount of white-fleshed cultivars is also in demand at the market. After 1990 much attention was paid to a valuable biochemical composition and good taste of peach fruits [5-7]. This paper presents the results of a study of introduced and local peach cultivars in a steppe Crimea with emphasis at fruit quality of peach cultivars with different ripening dates and biochemical composition of fruits. A brief description of who distinguished themselves in the study of cultivars and hybrids is also given.

\section{Materials and Methods}

Research was conducted on the base of the steppe plant growing laboratory in the steppe Crimea near the Simferopol (s. Novyj Sad) as recommended by Sedov and Ogolcova [8]. The climate here is mild, warm and arid [9]. Rainfall is not enough for the peach (average $481 \mathrm{~mm}$ in a year). The soil here is the southern black earth, being under fallow. Irrigation was carried out by furrows 1-2 times in a year. Cultural care performed in accordance with commonly accepted technology in that region. Biochemical studies have been performed at the biochemical laboratory of Steppe Department NBG following standard protocols [10]. A total dry solid was determined by drying at 100 degrees until a constant weight. Dry soluble substances of fruit were determined by the refract meter IRF-22. Organic acids were measured by titration with alkali solutions (titratable free acid is calculated as malic acid). Sugars (mono- and sucrose) determined according to Bertrand or Max-Muller (changed method of Bertrand). Vitamin "C" was defined by means iodated method and with a reagent of Tilmans. Quantitative and qualitative assessment of polyphenolic compounds and carotenoids was performed by spectrophotometry, by the absorption spectra hexane solutions in the area of 275-280 nm. Definition of catechins based on phloroglucinol reaction-formation of colored derivatives of vanillin (4-hydroxy-3-methoxybenzaldehyde by the reacting ring $\mathrm{A}$, which has an m-position $\mathrm{OH}$-group). Leucoanthocyanidins molecules were defined in the same manner (only, they are less colored). Obtaining of extracts polyphenolic compounds and carotenoids was carried using methods developed by the Department of Biochemistry NBG (Biochemistry Department of the NBG report 1985-1989).

\section{Results and Discussion}

More than 600 cultivars and hybrids of different eco-geographical groups are maintained at peach germplasm repository in the steppe Crimea. A total of 40 cultivars and hybrids from five periods of ripening were analyzed for content of basic biochemical components: solids, sugars, acids, polyphenolic compounds and vitamin C. The ripening period lasted for from the first of July to the second decade of August. Cultivars have been distributed in five groups of ripening: the ripening of fruits is in the period from 1 to 10 July, second - from 11 to 20 July, third-from 
21 to 31 July; fourth-from 1 to 10 August; fifth-from 11 to 20 August.

Peach fruits prized primarily for his sugar content, high levels of P-active compounds, organic acids, vitamins and minerals. Peach sugars include sucrose, glucose and fructose. Main active ingredients are flavonols, which determine the value of the fruit as food sources of P-active compounds. The peculiarity of flavonols (catechins and leucoanthocyanidins) is their high reactivity.

The solids content of peach fruits varied from $10.6 \%$ to $17.1 \%$ in Golgen and Ognenyiy respectively with the average $13.99 \%$. In some years, the amplitude of variation was wider, between 10.4 (Golgen) and $18.8(\mathrm{C} 1 / 227)$. This is consistent with the published data [11]. Cultivars Early Red Haven, Startovyiy, Miorita, Regina, 10848, Ognenyiy, Goldgem, C4/41, Sputnik, 7/221, Velvet and Kremlyovskiy were more stable in the number of dry matter at different years 1993, 1994 and 2012. Dry matter content increased by raising amounts of sugars. It is noted that some cultivars had a high content of dry matter and sugar in dry and hot years. These include Armgold (14.1\% and 10.2\%), Iftihor (17.0\% and $11.3 \%), 80-635$ (14.5\% and 13.2\%), 7/221 (16.6\% and $15.6 \%), \mathrm{C} 4 / 147$ (16.0\% and 12.7\%), Ognenyiy (20.2 and 13.4), С8/162 (15.0 and 12.0), С7/6 (15.0 и 10.3), C4/41 (15.9 and 11.2), C4/57 (18.0 and 14.4), $\mathrm{C} 1 / 227$ (18.8 and 15.7), C4/38 (16.4 and 12.6), C7/38 (17.6 and 12.7), C16/87 (17.0 and 12.9), V x FM 80-354 (18.4 and 12.7) and other.

Cultivars Kremlyovskiy, Regina, Velvet, hybrids $\mathrm{C} 7 / 38$ and $\mathrm{C} 4 / 57$ stood out by the number of sugars 13.6, 13.2, 12.9, 13.1 and 12.9\%, respectively (Tab. 1). Armgold, Iftihor, C1/227, Regina, Ambergold, C4/167 and $8 \mathrm{~A}$ were the most stable on the content of sugars.

The range of variation of the acid content is from 0.30 to 0.69 . Pushistyiy Ranniy (0.30), Goldgem (0.34), 80-607 (0.34), Kremlyovskiy (0.35), C8/263 (0.35), 8A (0.35) and C7/292 (0.36) are low acid cultivars. In line with the high acidity came Glohaven,
Ognenyiy (0.69), C4/110 (0.66), C4/41 (0.65), Early Red (0.64), and Vavilovskiy (0.63).

The most constant acid index was observed in different years in cultivars: 80-607, Kremlyovskiy, C7/6, Goldgem, Miorita, 8634, Regina, Pushistyiy Ranniy, C8/263 and C4/38. Cultivars Glohaven, Ognenyiy, C4/41 and Vavilovskiy had both high levels of sugar (10.1-11.6) and great acidity (0.63-0.69). The most balanced content of sugars and acids observed in cultivars with C4/41, Ognenyiy, Vavilovskiy, C4/57, C4/110, 10607, C7/38, Regina, Velvet, Early Red Haven, Miorita, Gloheyven, C1/227, $\mathrm{C} 4 / 12$ and 8634 . When tasting them there were a very rich harmonious taste and high degustation evaluations.

1993, 1994 and 2012 years were very dry. Small underdeveloped fruits had low poor biochemical parameters due to water deficit. It is noted that in drought years, contents of dry substances, sugars are increased in cultivars $\mathrm{C} 1 / 227, \mathrm{C} 7 / 292, \mathrm{C} 4 / 57$, Iftihor etc.

Acidity was heightened in $\mathrm{C} 4 / 110, \mathrm{C} 7 / 38$, Iftihor during the years of water shortages, acid had been reduced in $\mathrm{C} 1 / 227, \mathrm{C} 16 / 87$, Osvezchayuschiy and other.

The biochemical composition remained most stable in years with different weather and climatic conditions in cultivars Regina, Kremlyovskiy and Golgen.

Samples of peach with a high sugar content and acidity below 0.5 are of great interest. These include C4/12, Sputnik, RH x S80-635, C1/227, C7/6, C8/162, 81-813, C16/87, C4/64, 7/221, C4/147, Early Red Haven, Kremlyovskiy, Iftihor, C8/263 and 10848. When tasting them there were very informative rich sweet and sour taste with a predominance of sweet and high degustation evaluations.

There was a large variability of the content vitamin "C" by $9.2 \mathrm{mg} \%$ (the hybrid $81-813$ ) to $16.6 \mathrm{mg} \%$ (Glohaven). A more constant indicator of vitamin " $\mathrm{C}$ " marked in varieties Pushistyiy Ranniy, C8/263, C4/38, C4/167, Kremlyovskiy and C4/41. 
Table 1 Biochemical composition of peach fruits in the steppe Crimea.

\begin{tabular}{|c|c|c|c|c|c|c|c|c|c|c|c|c|c|c|}
\hline \multirow{2}{*}{$\begin{array}{l}\text { Cultivar, } \\
\text { hybrid }\end{array}$} & \multicolumn{2}{|c|}{$\begin{array}{c}\text { Soluble } \\
\text { solids, \% } \\
\end{array}$} & \multicolumn{2}{|c|}{$\begin{array}{c}\text { Total sugar, \% } \\
\text { aver }\end{array}$} & \multicolumn{2}{|c|}{ Total acid, \% } & \multicolumn{2}{|c|}{$\begin{array}{c}\text { Anthocyans } \\
\mathrm{mg} / 100 \mathrm{~g}\end{array}$} & \multicolumn{2}{|c|}{$\begin{array}{c}\text { Leucoan thocyans, } \\
\mathrm{mg} / 100 \mathrm{~g}\end{array}$} & \multicolumn{2}{|c|}{$\begin{array}{l}\text { Catechins, } \\
\mathrm{mg} / 100 \mathrm{~g}\end{array}$} & \multicolumn{2}{|c|}{$\begin{array}{c}\text { Vitamin "C", } \\
\mathrm{mg} / 100 \mathrm{~g}\end{array}$} \\
\hline & $\overline{\mathrm{AV}^{1}}$ & $\sigma^{2}$ & $\mathrm{AV}$ & $\sigma$ & $\mathrm{AV}$ & $\sigma$ & $\mathrm{AV}$ & $\sigma$ & $\mathrm{AV}$ & $\sigma$ & $\mathrm{AV}$ & $\sigma$ & $\mathrm{AV}$ & $\sigma$ \\
\hline \multicolumn{15}{|c|}{ Fruit ripening period $1-10.07$} \\
\hline $\mathrm{C} 4 / 12$ & 13.0 & 3.7 & 10.8 & 5.9 & 0.44 & 0.22 & 6 & 5 & 95 & 101 & 16 & 15 & 12.2 & 2.6 \\
\hline Armgold & 13.2 & 1.4 & 10.1 & 0.6 & 0.56 & 0.10 & 19 & 3 & 161 & 48 & 30 & 16 & 13.1 & 2.7 \\
\hline Aver & 13.1 & & 10.45 & & 0.5 & & 13 & & 128 & & 23 & & 12.6 & \\
\hline \multicolumn{15}{|c|}{ Fruit ripening period $11-20.07$} \\
\hline Iftihor & 12.2 & 1.1 & 9.2 & 0.6 & 0.41 & 0.12 & 25 & 36 & 140 & 43 & 34 & 29 & 12.9 & 2.4 \\
\hline $\mathrm{C} 4 / 41$ & 13.7 & 0.5 & 10.7 & 2.6 & 0.65 & 0.17 & 1 & 2 & 10 & 6 & 10 & 6 & 10.3 & 0.9 \\
\hline Startovyi & 15.3 & 0.0 & 8.1 & 1.3 & 0.55 & 0.34 & 13 & 4 & 154 & 129 & 48 & 65 & 15.8 & 3.4 \\
\hline Early Red & 12.8 & 1.9 & 7.9 & 2.1 & 0.64 & 0.25 & 22 & 22 & 50 & 20 & 8 & 5 & 13.5 & 2.7 \\
\hline Pushis. Ran & 13.6 & 0.8 & 9.0 & 1.2 & 0.30 & 0.09 & 12 & 11 & 226 & 88 & 67 & 18 & 16.3 & 0.3 \\
\hline Ognenyiy & 17.1 & 0.3 & 11.6 & 1.6 & 0.69 & 0.10 & 18 & 17 & 136 & 75 & 33 & 19 & 16.4 & 3.2 \\
\hline Sputnik & 11.9 & 0.6 & 11.8 & 2.3 & 0.41 & 0.10 & 39 & 61 & 67 & 52 & 8 & 4 & 12.1 & 1.6 \\
\hline 8634 & 13.9 & 2.9 & 9.2 & 2.0 & 0.50 & 0.08 & 9 & 4 & 179 & 134 & 44 & 37 & 12.1 & 2.7 \\
\hline $8 \mathrm{~A}$ & 13.8 & 1.3 & 8.4 & 0.9 & 0.35 & 0.10 & 13 & 4 & 185 & 109 & 37 & 27 & 15.3 & 2.5 \\
\hline $\mathrm{C} 7 / 6$ & 11.2 & 2.7 & 10.2 & 1.7 & 0.45 & 0.04 & 24 & 6 & 52 & 5 & 4 & 4 & 11.5 & 1.6 \\
\hline Aver & 13.6 & & 9.6 & & 0.495 & & & & & & & & 13.6 & \\
\hline \multicolumn{15}{|c|}{ Fruit ripening period 21-30.07 } \\
\hline 10607 & 14.5 & 2.3 & 10.9 & 1.1 & 0.57 & 0.15 & 1 & 2 & 153 & 113 & 51 & 67 & 12.6 & 1.2 \\
\hline Vavilovski & 12.7 & 3.0 & 10.1 & 2.5 & 0.63 & 0.27 & 7 & 6 & 113 & 68 & 61 & 66 & 10.2 & 2.0 \\
\hline $\mathrm{C} 1 / 227$ & 14.3 & 1.1 & 11.1 & 0.7 & 0.49 & 0.13 & 21 & 28 & 189 & 130 & 22 & 18 & 16.0 & 3.5 \\
\hline $\mathrm{C} 7 / 38$ & 16.7 & 2.1 & 13.1 & 3.0 & 0.59 & 0.11 & 0 & 0 & 191 & 94 & 21 & 10 & 11.0 & 2.9 \\
\hline $\mathrm{C} 7 / 292$ & 13.7 & 1.6 & 9.2 & 1.3 & 0.36 & 0.11 & 10 & 11 & 169 & 84 & 10 & 6 & 16.3 & 4.6 \\
\hline $\mathrm{C} 4 / 110$ & 12.9 & 2.3 & 9.9 & 3.2 & 0.66 & 0.18 & 6 & 6 & 119 & 37 & 18 & 3 & 13.1 & 2.9 \\
\hline Ambergold & 12.6 & 2.0 & 7.7 & 0.6 & 0.41 & 0.07 & 33 & 20 & 118 & 15 & 24 & 21 & 15.5 & 6.8 \\
\hline $\mathrm{C} 8 / 162$ & 14.2 & 3.2 & 11.8 & 2.3 & 0.44 & 0.07 & 18 & 18 & 123 & 58 & 16 & 13 & 13.4 & 3.4 \\
\hline $\mathrm{C} 4 / 38$ & 14.5 & 2.3 & 8.3 & 1.3 & 0.59 & 0.10 & 5 & 9 & 69 & 63 & 26 & 15 & 10.0 & 0.5 \\
\hline Golgen & 10.6 & 0.3 & 8.5 & 0.3 & 0.34 & 0.04 & 10 & 1 & 49 & 27 & 9 & 4 & 12.7 & 2.0 \\
\hline $\mathrm{C} 4 / 167$ & 14.1 & 1.1 & 9.4 & 0.9 & 0.60 & 0.11 & 6 & 6 & 83 & 56 & 10 & 11 & 15.9 & 0.6 \\
\hline $\mathrm{C} 4 / 147$ & 13.5 & 2.4 & 9.9 & 2.6 & 0.45 & 0.14 & 30 & 52 & 215 & 121 & 25 & 16 & 11.8 & 2.4 \\
\hline $81-813$ & 12.5 & 2.0 & 9.0 & 1.6 & 0.44 & 0.10 & 20 & 7 & 93 & 78 & 20 & 12 & 9.2 & 2.8 \\
\hline 8535 & 13.6 & 0.3 & 10.5 & 1.3 & 0.51 & 0.31 & 6 & 6 & 179 & 40 & 50 & 21 & 15.2 & 2.4 \\
\hline RxS80-635 & 14.1 & 2.4 & 10.0 & 2.7 & 0.47 & 0.09 & 9 & 5 & 312 & 136 & 111 & 47 & 15.3 & 6.3 \\
\hline Aver & 13.7 & & 10.0 & & 0.50 & & & & & & & & 13.2 & \\
\hline \multicolumn{15}{|c|}{ Fruit ripening period $1-10.08$} \\
\hline $\mathrm{C} 16 / 87$ & 15.7 & 1.5 & 12.2 & 2.5 & 0.43 & 0.18 & 5 & 4 & 141 & 138 & 48 & 65 & 13.9 & 1.6 \\
\hline $\mathrm{C} 4 / 64$ & 14.4 & 2.1 & 11.2 & 2.7 & 0.44 & 0.15 & 3 & 6 & 64 & 53 & 16 & 14 & 13.4 & 2.6 \\
\hline Early R.H. & 12.3 & 1.4 & 11.4 & 1.5 & 0.5 & 0.08 & 6 & 4 & 141 & 6 & 19 & 12 & 11.8 & 3.2 \\
\hline Miorita & 17.1 & 0.3 & 11.4 & 2.5 & 0.51 & 0.05 & 6 & 6 & 175 & 66 & 59 & 40 & 14.6 & 3.5 \\
\hline $7 / 221$ & 13.9 & 0.6 & 10.7 & 4.6 & 0.39 & 0.13 & 47 & 64 & 195 & 103 & 53 & 69 & 16.2 & 5.3 \\
\hline $80-607$ & 13.3 & 2.1 & 8.2 & 3.1 & 0.34 & 0.02 & 10 & 3 & 130 & 72 & 20 & 20 & 13.0 & 3.0 \\
\hline Aver & 14.5 & & 10.8 & & 0.44 & & & & & & & & 13.8 & \\
\hline \multicolumn{15}{|c|}{ Fruit ripening period $11-21.08$} \\
\hline $\mathrm{C} 8 / 263$ & 12.5 & 1.5 & 9.8 & 2.0 & 0.35 & 0.10 & 6 & 1 & 80 & 36 & 13 & 6 & 9.3 & 0.4 \\
\hline Kremlyovs & 16.0 & 1.0 & 13.6 & 2.3 & 0.35 & 0.04 & 9 & 4 & 179 & 24 & 130 & 129 & 11.7 & 0.8 \\
\hline $\mathrm{C} 4 / 57$ & 15.7 & 1.7 & 12.9 & 3.1 & 0.56 & 0.21 & 11 & 6 & 137 & 70 & 33 & 23 & 14.9 & 2.1 \\
\hline Velvet & 16.6 & 0.8 & 12.9 & 1.8 & 0.53 & 0.22 & 11 & 7 & 194 & 202 & 62 & 66 & 14.5 & 4.0 \\
\hline Glohaven & 14.6 & 1.8 & 11.3 & 2.3 & 0.69 & 0.29 & 10 & 8 & 95 & 37 & 46 & 45 & 16.9 & 7.4 \\
\hline Regina & 15.5 & 0.3 & 13.2 & 1.0 & 0.64 & 0.09 & 14 & 6 & 76 & 21 & 13 & 8 & 14.7 & 1.2 \\
\hline 10848 & 15.4 & 0.3 & 10.5 & 2.4 & 0.47 & 0.23 & 4 & 4 & 143 & 143 & 54 & 81 & 16.4 & 8.4 \\
\hline Aver & 15.0 & & 12.1 & & 0.52 & & & & & & & & 13.9 & \\
\hline
\end{tabular}

${ }^{\mathrm{AV}-\text { Aver means; }}$

${ }^{2} \sigma$-Standard deviation. 
When grouping of cultivars to according terms ripening, some trends in solids content, sugars, acids and vitamin "C" have been found. Results are presented in the diagram (Fig. 1).

Peach cultivars and hybrids differ by the content of dry matter and sugars, as can be seen in Fig. 1. In the main dry matter of later ripening cultivars was higher than of earlier ripening ones, $15 \%$ and $12 \%$ accordingly, average amount of sugar was higher in later maturing cultivars than earlier ripening, 12.07 and 9.13 accordingly. This is consistent with date of Ref. [11].

The total acidity of the fruit also varies within 0.53 and 0.47 , and it is higher in cultivars ripening in early July (0.53), and lower in cultivars ripening in the second and third of July (respectively 0.52 and 0.51 ). The acidity is lowest $(0.47)$ in cultivars ripen in early August, and the acidity is heightened-ripening later (0.52). The acidity of the fruit flesh remains essentially on the same level in the other periods 0.51-0.53. Comparable results have been obtained on the southern coast of Crimea.

According to the content of vitamin " $\mathrm{C}$ " was observed variations from 9.2 to $16.9 \mathrm{mg} / 100 \mathrm{~g}$ depending on the cultivar, the ripening group and the year.

In general, medium-ripening fruits (1.08-3.08) were more delicious due to harmonious (balanced) the content of sugars and acids, P-active substances and vitamin "C" [5]. Peach and plum fuits were practically identical in the qualitative composition of the major carotenoids: most of carotenoids were carotene. Carotene have been identified in a number of cultivars and hybrids: C4/38 (3.0), Glohaven (1.59 mg\%), Earley Red Haven (1.15 mg\%), Startovyiy (1.15 mg\%), C4/41 (0.66-1.00), C8/162 (0.79-1.04), C4/110 (0.31-1.67), C4/12 (0.84), Zlatna Krichimka (0.51), Armgold (0.41-0.93 mg\%), 8535 (0.42-0.97 mg\%), Goldgem (0.39), 8636 (0.36) and other. C7/38, C8/263, Goldgem, 80-607, Armgold, Kremlyovskiy and C7/6 appeared the most stable by the number of anthocyanins.

Cultivars Early Red Haven, C7/6, Ambergold, Kremlyovskiy, 8535 and C4/110 were more constant according the leucoanthocyanins content. Catechins are the most instable components. Much of variability was marked by years, even within the class. A smaller variability of this indicator by years is found in Pushistyiy Ranniy and C4/110.

Brief characteristics of peach fruits cultivars and advanced perspective hybrids are presented in Table 2.

In general, descriptions of the cultivar-etalon appearance Early Red Haven comply with the authors from the Balkan countries, but ripening of fruits in the Crimea comes later nearly a month [12].

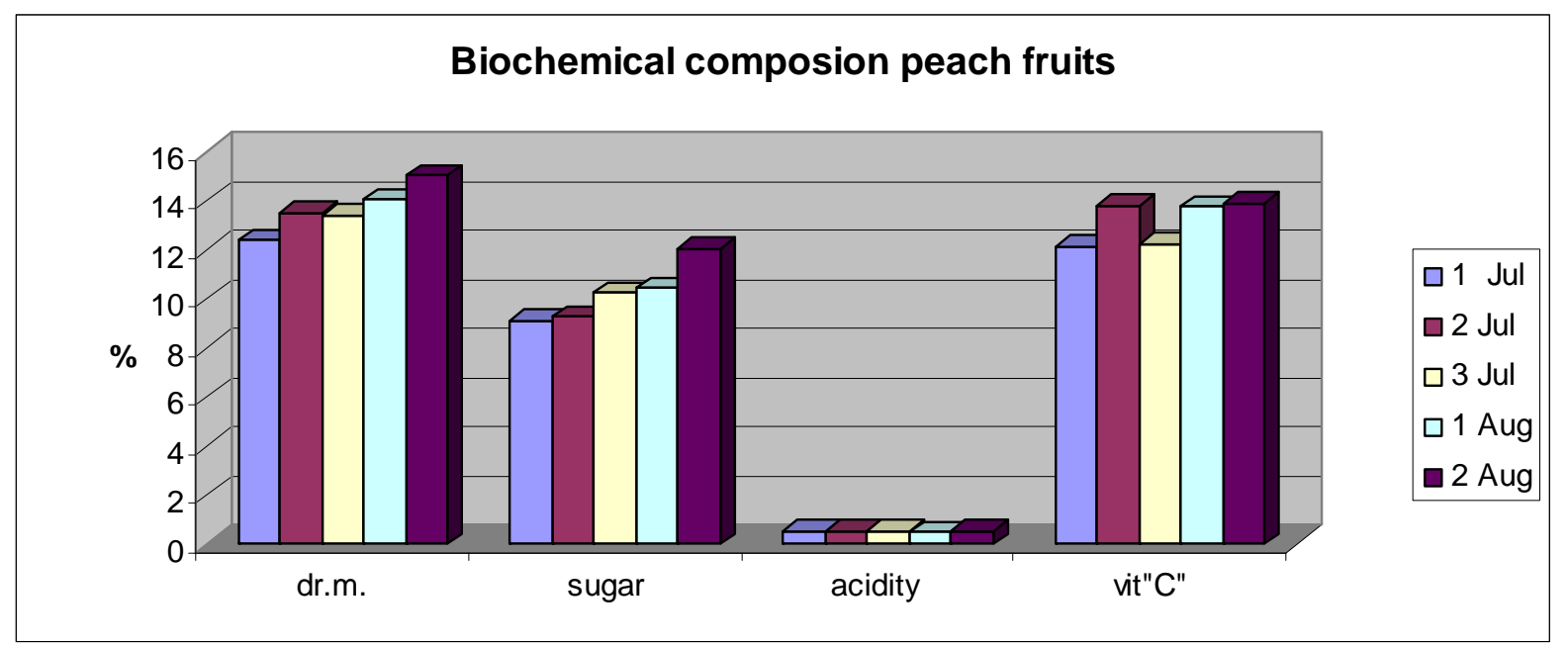

Fig. 1 Main biochemical parameters peach cultivars of different terms ripening in the climatic conditions of the steppe Crimea. 
Table 2 Brief characteristics of peach cultivars and hybrids fruits in the Steppe Crimea.

\begin{tabular}{|c|c|c|c|c|c|c|c|c|}
\hline \multirow[b]{2}{*}{ Cultivar, hybrid } & \multirow{2}{*}{$\begin{array}{l}\text { Fruit repining } \\
\text { period, d.m. }\end{array}$} & \multicolumn{7}{|c|}{ Brief characteristics of fruits } \\
\hline & & Weight, g & Shape $^{2}$ & $\begin{array}{l}\text { Covering } \\
\text { color, } \%\end{array}$ & $\begin{array}{l}\text { Flesh } \\
\text { color }^{3}\end{array}$ & $\begin{array}{l}\text { Consistency } \\
\text { of flesh }\end{array}$ & $\begin{array}{l}\text { Adherence } \\
\text { to flesh }\end{array}$ & Taste $^{6}$ \\
\hline Iftihor & 2.07 & 125 & $\mathrm{R}$ & 15 & $\mathrm{Y}$ & $\mathrm{M}$ & $\mathrm{C}$ & 4.4 \\
\hline Ognenyiy & 2.07 & 130 & $\mathrm{R}$ & 75 & $\mathrm{Y}$ & M & $\mathrm{C}$ & 4.3 \\
\hline $\mathrm{C} 7 / 6$ & 2.07 & 120 & $\mathrm{R}$ & 85 & W & M & $\mathrm{C}$ & 4.5 \\
\hline Startovyi & 2.07 & 140 & $\mathrm{R}$ & 57 & $\mathrm{Y}$ & M & $\mathrm{F}$ & 4.7 \\
\hline $80-635$ & 3.07 & 130 & $\mathrm{R}$ & 57 & W & M & $\mathrm{C}$ & 4.2 \\
\hline 10607 & 3.07 & 140 & $\mathrm{R}$ & 65 & $\mathrm{Y}$ & M & $\mathrm{C}$ & 4.8 \\
\hline $\mathrm{C} 4 / 38$ & 3.07 & 125 & $\mathrm{R}$ & 0 & Y & M & $\mathrm{F}$ & 4.5 \\
\hline $\mathrm{C} 7 / 38$ & 3.07 & 150 & $\mathrm{R}$ & 0 & Y & M & $\mathrm{F}$ & 4.4 \\
\hline $\mathrm{C} 1 / 227$ & 3.07 & 160 & $\mathrm{R}$ & 50 & $\mathrm{Y}$ & M & SF & 4.6 \\
\hline $\mathrm{C} 4 / 147$ & 3.07 & 145 & $\mathrm{R}$ & 85 & Y & M & $\mathrm{F}$ & 4.8 \\
\hline Vavilovskiy & 3.07 & 250 & $\mathrm{R}$ & 80 & Y & M & SF & 4.8 \\
\hline Early Red Haven & 1.08 & 155 & $\mathrm{R}$ & 70 & Y & M & $\mathrm{F}$ & 4.6 \\
\hline $\mathrm{C} 16 / 87$ & 1.08 & 165 & $\mathrm{R}$ & 55 & Y & M & $\mathrm{C}$ & 4.7 \\
\hline $\mathrm{C} 4 / 64$ & 1.08 & 155 & RO & 50 & $\mathrm{Y}$ & M & $\mathrm{F}$ & 4.5 \\
\hline Miorita & 1.08 & 169 & $\mathrm{R}$ & 67 & $\mathrm{Y}$ & M & $\mathrm{F}$ & 4.4 \\
\hline $\mathrm{C} 4 / 57$ & 2.08 & 180 & $\mathrm{R}$ & 60 & $\mathrm{Y}$ & M & $\mathrm{F}$ & 4.6 \\
\hline Osvezchayuschiy & 2.08 & 163 & $\mathrm{R}$ & 50 & $\mathrm{Y}$ & M & $\mathrm{F}$ & 4.8 \\
\hline Kremlyovskiy & 2.08 & 158 & $\mathrm{R}$ & 55 & $\mathrm{Y}$ & M & $\mathrm{F}$ & 4.8 \\
\hline \multicolumn{9}{|c|}{$\begin{array}{l}{ }^{2} \text { d.m.- decade of the month, a month; } \\
{ }^{2} \mathrm{R} \text {-round, O-oval, RO-rounded oval; } \\
{ }^{3} \mathrm{Y} \text { - yellow-fleshed, } \mathrm{W} \text { - white-fleshed; } \\
{ }^{4} \mathrm{M} \text { - melting flesh consistency; } \\
{ }^{5} \mathrm{~F} \text { - Freestone, SF-Semi-freestone, } \mathrm{C} \text {-Clingstone; } \\
{ }^{6} \text { - An average value on a 5-point-scale. }\end{array}$} \\
\hline
\end{tabular}

\section{Conclusion}

As a result of studies peach cultivars with a high content of sugar in the fruit under the steppe Crimea have highlighted: Kremlyovskiy (13.6), Regina (13.2), Velvet (12.9), hybrids C7/38 (13.1) and C4/57 (12.9). Cultivars with an increased sugar content and low organic acids C4/12, Sputnik, RHxS80-635, C1/227, C7/6, C8/162, 81-813, C16/87, C4/64, 7/221, C4/147, Early Red Haven, Kremlyovskiy, Iftihor, C8/263 and 10848 were selected.

Cultivars and hybrids with an increased sugar and low acidity under water deficit (in the years of drought) were revealed: $\mathrm{C} 4 / 12$ (15.9 and 0.32), $\mathrm{C} 1 / 227$ (15.7 and 0.37), C16/87 (12.9 and 0.23), C4/147 (12.7 and 0.44), C8/162 (12.0 and 0.38), C8/263 (10.3 and 0.36), C7/292 (10.4 and 0.38), C4/64 (10.4 and 0.42) and C7/6 (10.3 and 0.44).
Cultivars Regina, Kremlyovskiy and Golgen have demonstrated the highest stability on basic biochemical parameters of fruits in years of research. Cultivars and hybrids of peach 10607, C1/227 C7/38, C7/6, C8/162, C4/147, C16/87, C4/64, Early Red Haven, Miorita, 7/221, Kremlyovskiy, 10848 are characterized by the best biochemical and morphological indices of fruits in the conditions of steppe Crimea. They are recommended for State cultivar testing or use in breeding work to improve the quality of peach fruits.

\section{Acknowledgement}

This study was funded by the research grant No. 14-50-00079 of the Russian Science Foundation.

\section{References}

[1] Ryabov, V. A. 2004. "The Crimean Agro Climatic 
Potential for Fruit Crops." In Conference Proceedings Optimization of Ecological Conditions in Horticulture, Russia, Yalta: NBG, 85-7.

[2] Latsko, T. A. 2004. "Needs of Peach Cultivars to the Warmth." In Conference Proceedings Optimization of Ecological Conditions in Horticulture, Russia, Yalta: NBG, 67-70.

[3] Hesse, C. O. 1975. "Peach." In Advances in Fruit Breeding. West Lafayette, Indiana: Purdue University Press, 390-462.

[4] Iglesias, I. 2013. "Peach production in Spain: Current Situation and Trend, from Produkton to Consumption." In Proceedings of the 4th Conference, Innovation in Fruit Growing, Belgrade, 75-98.

[5] Smykov, V. K., Smykov, A. V., Latsko, T. A., Richter, A. A., Lobanovskaya, V. F., and Fedorova, O. S. 2010. "Genefond of Peach Culture and Its Using in Selection." In Genefond of South Fruit Crops and Its Use. Works Nikit. Botan. Gard. 132: 19-33.

[6] Cipriani, G., Terlizzi, M., Bevilacqua, D., Di Cintio, A., Rose, T., and Sartori, A. 2015. "Peach Breeding Programmer for New and Different Traits. Pomological,
Phenological and Date Analysis with a Ranking Method." Acta Hortic. 1099: 695-702. http://dx.doi.org/10.17660/actahortic.2015.10099.86.

[7] Liverani, A., Brandi, F., Quacquarelli, I., Sirri, S., and Giovannini, D. 2015. "Superior Taste and Keeping Quality Are Steady Goals of the Peach Breeding Activity at CRA-FRF." Acta Hortic. 1084: 179-86. http://dx.doi.org/10.17660/actahortic.2015. 1084.24.

[8] Sedov, E. N., and Ogolcova, T. P. 1999. Program and Methods of Cultivar Investigation of Fruit, Berry and Nut Crops. Orel, Russia: VNIISPK, 606.

[9] Antyufeyev, V. V., Vazhov, V. I., and Ryabov, V. A. 2002. The Reference Book about Climate of the Steppe Department of Nikitsky Botanical Gardens. Yalta: NBG, 87.

[10] Lane, Z. Y. 1970. "Methods Chemical Analyses of Varieties and Hybrids." In Metodology State Strain Testing of Crops, Vol. 7. Mos.: The Ministry of Agriculture, 176.

[11] Andrienko, M. V. 1997. "Pomology." In Apricot, Peach and Cherry-Plum, Vol. 3. Ukrane: Urozchay, Kiev, 80-198. ISBN 5-337-00519-7.

[12] Mratinić, E. 2012. Breskva. Partenon, Beograd. 665. 